\title{
Die Psalms: soorte, funksie, aard en die omdigting van Psalm 131
}

\author{
C.J.A. Vos
}

Fakulteit Teologie

Universiteit van Pretoria

PRETORIA

E-pos: teolb@ccnet.up.ac.za

\begin{abstract}
Psalms: types, function, character and the versification of Psalm 131

The publishing of Liedboek van die kerk (2001) has emphasised the importance of the Psalms for the liturgy and the hymnology. This article considers the following aspects: the bridge function of the psalms; the significance and function of the psalms as an open hymnbook and as an anthology; and the literary types found in the psalms. The structure and form of Psalm 131 are analysed in greater detail. This analysis leads in conclusion to a literary evaluation of its versification by T.T. Cloete.
\end{abstract}

\section{Aktualiteit}

Die belangrikheid van die psalms vir die liturgie en himnologie is deur die verskyning van die Liedboek van die Kerk (2001) onderstreep. ${ }^{1}$ Hierdie publikasie het onder andere meegebring dat die psalms as gedigte en liedere opnuut bestudeer is ten opsigte van die literêre, liturgiese en himnologiese fasette daarvan.

In hierdie artikel word daar agtereenvolgens gefokus op die brugfunksie van die psalms; die betekenis en funksie van die psalms in die liturgie; die samestelling van die psalmboek en die literatuursoorte van die psalms. Ook word op die struktuur en die uitleg van Psalm 131 gelet. Ten slotte word T.T. Cloete se omdigting van Psalm 131 kortliks bespreek op grond van literêre oorwegings.

1 In die Liedboek is al 150 psalms deur T.T. Cloete omgedig, afgesien van enkele ander omdigtings deur onder ander Lina Spies en Antjie Krog. 


\section{Die brugfunksie van die psalms}

Die psalms vervul in vele opsigte 'n brugfunksie tussen uiteenlopende soorte denominasies wat mekaar vroeër op een of ander manier vermy het (Schuman, 1995:1). Die psalms is liedere wat in die Joodse en die Christelike tradisie, in die Oosters-Ortodokse en Westerse kerke, in die Rooms-Katolieke tradisie en vele Reformatoriese strominge 'n sleutelplek gekry het (Schuman, 1998b:374-375; Kaspar, 1999:96). Die psalms verbind mense uit verskillende wêrelde, tradisies en tye (Vos, 2001:358). Die sing van die psalms in die erediens herinner ons ook steeds aan die sapryke wortels van Israel, die Jodendom, die tempel en die sinagoge (Barnard, 1985:66-102; Schuman, 1998b:375).

\section{Psalms in die liturgie}

Nadenke oor die betekenis en funksie van psalms in die liturgie lei daartoe dat psalms ook met liturgiese oë bekyk word. Naas die ekumeniese brugfunksie wat die psalms vervul, het die nuwe belangstelling in die liturgie ook die vraag na die betekenis en funksie van psalms in die liturgie onder die aandag gebring (Schuman, 1998a:165; 1998b:377-378; 2001:250-252). In die "ekumenies-Protestantse" kerke word daar in die liturgie na "die psalm van die Sondag" verwys wat in die liturgiese jaartema die patroon van die erediens kan bepaal; dit word dan as proprium saam met ' $n$ besondere teks as keervers en saam met die "gebed van die Sondag" aangegee (Schuman, 1998a:166-167; Monsma, 1998:423-449).

\section{Psalms as liedboek}

Psalms is in die tempel gesing deur 'n gilde sangers wat deur musici begelei is. Met Paastyd (ook tydens die Loofhuttefees) is die Hallel gesing (Pss. 113-118). In dié verband kan ook verwys word na die lofsang in Matteus 26:30, wat ná die Nagmaal gesing is (Vrijlandt, 1989:22).

Op pad na die tempel waar die Pinkster- of die Loofhuttefees gevier is, is pelgrimsliedere gesing (Pss. 120-134). Daar is ook oor die vreugde van die Wet gesing (Pss. 1; 19; 119). Psalm 92 is die psalm vir die sabbatmôre, terwyl Psalms 95-99 die vorige aand gesing is (Vrijlandt, 1989: 22).

Die psalms was die gebede en liedboek van Israel en die Jodedom en ook van Jesus (vgl. Ps. 22) en sy volgelinge. Die Christelike kerk het die bundel psalms oorgeneem. In die ryk tradisie van die Christendom leef ons daarom ook uit die inhoud van die psalms (Schuman, 1998a:166167; Monsma, 1998:423-425). 
Tans behoort die rykdom wat die Psalms as liedboek bied, weer ontdek en ontgin te word. Die vanselfsprekende rede hiervoor is dat al die geloofstemas in die psalms voorkom. Die diepste menslike emosies weerklink in die psalms: vreugde en dank, maar ook pyn en vrees in krisissituasies. Sommige psalms druk jubelende lofprysing aan God uit, terwyl ander teen God kla; in party psalms word oor die skoonheid van die lewe en goeie verhoudings tussen mense gesing; ander psalms praat van die gebroke verhoudinge tussen mense - selfs van wraak teen vyande; daar is psalms waarin tot God gebid word, maar ook psalms wat die goddelose vervloek. In die psalms word ook met die onopgeloste raaisels van die lewe geworstel, soos die vraag waarom die regverdige onder laste moet swig terwyl die goddelose ligvoets en voorspoedig deur die lewe gaan. Die Psalms is 'n boek wat die verhaal van God en mens se omgang met mekaar vertel. Die bundel Psalms is bo alles geloofsgesange oor sonde en genade. Hierdie momente word in die nuwe omdigtings van die Psalms as 'n georganiseerde en organiese geheel op 'n verantwoordelik wyse verwoord.

\section{Die Psalms as digbundel}

Net soos gedigte in 'n bundel nie los eenhede is nie, maar deel van 'n groter geheel is, is dit die geval met die psalms. Duidelike aanduidinge bestaan dat die komposisie van die Psalmbundel nie by een geleentheid plaasgevind het nie. Daar is aanwysers dat vroeëre versamelings bestaan het wat later in ons bundel saamgevoeg is. Ons vind byvoorbeeld dat 'n aantal psalms gedupliseer is: Psalm $14=$ Psalm 53; Psalm 40:13-17 = Psalm 70 en Psalm 108 = Psalms 57:7-11 + Psalm 60:5-12. Hierdie verskynsel is verklaarbaar indien die gedupliseerde psalms oorspronklik tot verskillende versamelings behoort het.

Die bundel Psalms bestaan uit vyf onderafdelings wat elk met 'n doksologie sluit (Zenger, 1997:25):

\begin{tabular}{llll} 
Psalm 1-2 & - & \multicolumn{2}{c}{ inleiding tot die psalmbundel } \\
Psalms 3-41 & - & doksologie: & $41: 14$ \\
Psalms 42-72 & - & doksologie: & $72: 18-19$ \\
Psalms 73-89 & - & doksologie: & $89: 53$ \\
Psalms 90-106 & - & doksologie: & $106: 48$ \\
Psalms 107-150 & - & Psalm 150 vervul die funksie van die \\
& & \multicolumn{2}{c}{ doksologie }
\end{tabular}

Psalms 3-41 is die eerste groot versameling en staan as Boek 1 bekend. Hierdie groepering staan as die Dawidsversameling bekend omdat, met 'n enkele uitsondering (Ps. 33), Dawid se naam in al die ander opskrifte voorkom. ' $n$ Ander kenmerk van dié groep is dat die goddelike Naam, Jahwe (Here) deurgaans gebruik word. In Boek 2 word die volgende 
psalms ook aan Dawid toegeskryf: 51-65 en 68-70. In Boek 3 word Psalm 86 op Dawid se naam geplaas terwyl boek 4 Psalm 101 en 103 op sy rekening plaas. In die vyfde versameling word Psalm 108-110, 122, 124, 131 en 138-145 aan Dawid toegeskryf.

Die laaste afdeling het nie 'n spesifieke doksologie nie. Die rede is dat die hele Psalm 150 die funksie vervul. Elk van die onderafdelings word afgesluit deur 'n lofroep, en dié doksologieë verbind die gedigte in elke afdeling weer onderling. Soms, soos in die geval van Psalm 41, wat 'n smeking in nood is, en Psalm 89, wat op 'n toon van verwyte en aanvegting eindig, kom die doksologie in verrassende kontekste voor. Wat is die sin van 'n lofroep in só 'n konteks? Juis die lofklank in dié konteks toon dat al die psalmsoorte - klagte, smekinge, verwyte, liturgieë, individuele gebede, kollektiewe liedere, wysheids- en vertrouenspsalms - en al hul motiewe versier word deur die motief van lof aan God. Dit is ook nie vreemd dat die bundel later die titel tehillîm (Lofliedere) gekry het nie - ten spyte van liedere gevul met smart (soos Psalm 38), wraaksug (soos Psalm 70), uitsigloosheid (soos Psalm 88), klagte (soos Psalm 130) en bitterheid (soos Psalm 137). Psalm 150 is nie alleen die spitspunt van die groep hallelujapsalms (Psalms 146-150) nie, maar dit is ook ' $n$ volledige doksologiese psalm om die hele bundel mee af te sluit.

Die vyf afdelings in die Psalmboek hang saam. Verder vorm verskillende psalms 'n samehang. Schuman (1998b:375-376) toon ook aan hoe die Bedevaartpsalms met mekaar saamhang en in mekaar verweef is.

\section{1 Pelgrimspsalms - van Mesek na Jerusalem}

Psalms 120-134 vorm die pelgrimspsalms. Daar word in hierdie artikel aan dié groep psalms aandag gegee omdat Psalm 131 waarna later in die artikel verwys word (paragraaf 7 en 8 ), in dié versameling voorkom. Die eerste drie psalms (Psalm 120-122) in dié groep pelgrimspsalms, verteenwoordig drie stasies op dié reis; dit vertel hoe die reispad loop (Schuman, 1998a:375). In Psalm 120:5 roep iemand uit: "Hoe ellendig was dit toe ek as vreemdeling in Mesek gewoon het ...". Eintlik weet ons nie waar om dié plek op 'n landkaart te soek nie. Mesek en Kedar staan vir onherbergsaamheid, ja vir onleefbaarheid, ballingskap, vervreemding. Hier ervaar iemand teëspoed in 'n vyandige gebied. Hier is die lewe nie goed nie: haat, nyd en gevare heers. Die "ek" van Psalm 120 soek na vrede, sjalom, maar moet tog die weeklag laat hoor: "Helaas, ek moet leef in Mesek ... té lank moes ek woon met heimwee" (vgl. Schuman, 1998a:376). Die reisiger kan egter nie net in Mesek bly nie; hy moet verder reis. In die volgende lied, Psalm 121, kry dié verhaal 'n vervolg: 
die ek-spreker kyk na die berge vir hulp, want die berge was destyds gesien as die blyplek van die gode (Prinsloo, 1984:110).

Van die gode is daar geen hulp te verwag nie. Daar is net een uitweg: "My hulp kom van die Here". Hy is die Maker van die hemel en die aarde. En Hy is by jou. Hy sal die reisiger beskerm en bewaar. Die Here slaap nooit nie en Hy sluimer nie in nie. Hy sal die reisiger van alle gevare bewaar. Die Here sal die reisiger teen die gode en bedreiginge, die son en die maan, bewaar. Hulle sal hom nie kwaad aandoen nie - al kyk die son met sy bloedbelope oog na hom en al wil die maan onheil oor hom laat skyn. Die Here sal sy uitgang en sy ingang bewaar. Hy sal die reisiger lei op sy uittog deur die onherbergsame land oor die berge tot by sy bestemming.

Die bestemming van die reis word in Psalm 122:1-2 aangedui: "Ek was bly toe hulle vir my gesê het: 'Kom ons gaan na die huis van die Here toe'" (Schuman, 1998a:376). In Psalm 131 word die rus wat die reisigers by die Here vind, beskryf. In Psalm 133 word die eensgesindheid van broers wat saamwoon gevier. Die liturgiese beeld uit die tempel van Jerusalem verduidelik beeldend die innigheid van die saamwoon van broers. Die pelgrimspsalms word afgesluit deur 'n diens aan en seën van God in Jerusalem (Ps. 134). Die uiteinde van die reis word geïmpliseer deur die woorde: "En nou is ons binne-in jou, Jerusalem". Die reis wat afgelê is, was van Mesek tot in Jerusalem. Dáár word die tuiskoms van reisigers gevier. In Jerusalem is die reisigers nie meer alleen nie: hulle is in die geselskap van ' $n$ feesvierende skare. In die pelgrimspsalms is ' $n$ spesifieke roete gevolg: uit Mesek, oor die berge en gevare, na die stad van vrede, na Jerusalem toe. Jerusalem as eindbestemming verteenwoordig God in sy heerlikheid.

Die nag was die tyd van afskeid na die godsdienstige fees. Maar voordat die pelgrims die nagrus opsoek, om dan vroegmôre die terugtog na hulle dorpe en stede aan te pak, gee hulle 'n opdrag aan die diensdoenende priesters en Leviete. Hulle versoek die priesters en Leviete om die Here in 'n naglied te seën (Ps. 134:1; Zenger, 1997:364). Om die seënende krag van die Here lofprysend te erken (Zenger, 1997:365), vra om 'n Beraka, 'n lofspreuk.

Die tweede liturgiese handeling (Ps. 134: 3 ) is in die vorm van 'n gebed, 'n epiklese (Zenger, 1997:366). Dit is die antwoord van die priester. Dit is ook die begin van die Aäronitiese seën (vgl. Num. 6:24-26). Die Here se lewensbeskerming en lewenshulp word uit Sion toegesê. Die seker wete van die nabyheid van die Skeppergod sal die pelgrims op die alledaagse lewe begelei. Op pad neem hulle die Here se seën as sy geskenk saam. 
En op pad sal die Here se seën hulle bewaar - dié seën wat hulle ook aan mekaar in die alledaagse lewe uitdeel (Zenger, 1997:366).

\section{Die literatuursoorte van die Psalms}

Onder literatuursoort word die tekssoort verstaan. Die tekssoort dui aan hoe dit verstaan moet word. Elke tekssoort gebruik bepaalde teksstrategieë met die oog op die kommunikasie aan die leser of hoorder. 'n Begrafnisberig sal byvoorbeeld nie van ironie en satire gebruik maak nie. In 'n komedie is dié strategieë wel op sy plek. Benewens die teksaanbod wat 'n bepaalde literatuursoort maak, skep dit ook by die leser 'n sekere verwagting oor die verstaan en ervaring daarvan. 'n Leser lag nie vir 'n begrafnisberig nie, maar wel vir 'n satire (Vos, 1996:41).

In die boek Psalms kan verskillende tekssoorte onderskei word. Daar is byvoorbeeld himniese, klaag-, wysheids- en vertrouenspsalms. Daar kom dikwels ook mengvorme voor, soos byvoorbeeld wysheids- en vertrouensperspektiewe in een psalm. 'n Klaagpsalm kan ook byvoorbeeld lof-elemente bevat (vgl. Ps. 13). Elke psalmsoort is die draer van 'n bepaalde boodskap. Die boodskap moet in elke psalmsoort, maar ook in elke afsonderlike psalm gesoek word.

Lof vorm die hartklop van talle psalms. Die volgende himnes kan onderskei word: Psalm 8, 29, 33, 46-48, 65, 68, 76, 84, 87, 93, 95-100, 103$104,113-114,117,122,134-136$ en 145-150. Gewoonlik mond die klag ook in lof uit.

In hierdie artikel word ook na Psalm 131 vanuit 'n literêre hoek gekyk. Dit beteken dat die literatuursoort, die struktuur en die poëtiese strategieë en konvensies sowel as die betekenis en funksie van dié psalm in berekening gebring word. 'n Literêre benadering neem ook in ag dat dié enkele psalm deel vorm van 'n geheel, 'n digbundel.

\section{Die struktuur en uitleg van Psalm 131}

Psalm 131 is 'n veroordeling van menslike hoogmoed of selfverheffing (Van der Ploeg, 1974:385). Dit is die gebed van iemand wat vrede gevind het in die Here - in so 'n mate dat hy niks meer begeer as om die Here se wil te doen nie. Psalm 131 is 'n vertrouensgebed (Prinsloo, 1991:86) wat ook didakties-paranetiese trekke vertoon (Beyerlin, 1982: 88). Die didaktiese aard van die teks beoog om die ontvangers van die teks te oorreed sodat hulle hulle selfverheffing sal prysgee en op die Here vertrou (Prinsloo, 1991:86).

Die sentrale tema van dié psalm, naamlik die afwysing van selfverheffing, word in verse $1 \mathrm{~b}-1 \mathrm{c}$ vanuit 'n negatiewe perspektief belig 
(Van der Ploeg, 1974:385; Prinsloo, 1991:88; Seybold, 1996:495; Viviers, 1998:678). Die digter noem watter kenmerke hy nie het nie, en herhaal dit drie maal:

my hart is nie hoog nie

my oë is nie trots nie

ek maak my nie besorg oor dinge wat bo my vermoë is nie.

Met "hart" word die digter se denke en emosies bedoel. "Oë" is die orgaan waaruit selfverheffing skyn. Met sy oë sien 'n mens neer op ander. Deur die dubbele negatief te gebruik, verwerp die digter enige sweem van selfverheffing teenoor sy naaste (Van der Ploeg, 1974:386; Prinsloo, 1991:88; Viviers, 1998:679). In die derde versreël verwys die uitdrukking "dinge bo sy vermoë" na die groot en wonderlike heilsdade van die Here (Prinsloo, 1991:88). As die digter dit op homself toepas, bedoel hy dat hy hom nie teenoor God verhef nie. Hy ken sy plek voor God en waag dit nie op God se terrein nie.

Die tema van die psalm word in vers $2 a$ positief verduidelik:

Ek het rus en kalmte gevind.

Dié bewering word in vers $2 \mathrm{~b}$ deur middel van 'n pragtige vergelyking geillustreer:

Soos 'n kindjie wat by sy moeder

tevredenheid gevind het,

so het ek tevredenheid gevind.

Die rus en kalmte word verduidelik deur die vergelyking van hoe 'n kindjie by sy ma tevredenheid vind (Kraus, 1966:875). Ná die voeding kreun 'n kind van genoegdoening in sy ma se arms (Van der Ploeg, 1974:386). In sy ma se arms vind hy sekuriteit, tevredenheid en geluk. Net so het die digter vrede met homself en God (Prinsloo, 1991:88). Die vrede is 'n innige en innerlike vrede wat hy uitstraal.

Vers 3 is ' $n$ liturgiese byvoeging. Die digter deel sy rus en kalmte met Israel (Seybold, 1996:495). Die verband tussen die persoonlike en die gemeentelike bestaan daarin dat die digter sy persoonlike oortuiging en ervaring nie vir homself hou nie, maar aan die gemeente meedeel. Daarom is vers drie 'n paranetiese oproep aan Israel (Kraus, 1966:875; Prinsloo, 1991:88; Viviers, 1998:681-682). Israel word opgeroep om te "wag op die Here". Hulle moet in afhanklikheid van die Here leef en voordurend op Hom bly hoop. 


\section{Die omdigting van Psalm 131 (T.T. Cloete)}

Geen strewe jaag ek na bo my vermoë, geen trots of hoogmoed is daar in my oë.

Sal ek die groter dinge wil oortref

en sal ek my, o Heer, teen $U$ verhef?

'n Kind rus in sy moeder se beskerming.

So vind ek vrede, Heer, in u ontferming.

Wag, Israel, vertrou Hom deurentyd.

Wag op die Here tot in ewigheid.

\section{1 'n Literêre beoordeling}

In die Cloete-omdigting word die Hebreeuse gedig in twee strofes weergegee. Cloete maak van 'n aabb-rymskema gebruik. Die "trots" of "hoogmoed" word as sinonieme beskou en hierdie begrippe word met die "oë" verbind. Op hierdie manier word die gedagte van neersien op ander poëties verwoord. Deur hierdie omdigtingswyse is Cloete getrou aan die sentrale motief van die psalm, naamlik die afwysing van selfverheffing. In die derde en vierde versreëls van strofe 1 gee die omdigter uitdrukking daaraan dat die ek-spreker hom nie teen die Here verhef nie. Ook in hierdie opsig is die omdigting getrou aan die Hebreeuse psalm. Cloete verwoord die feit dat die ek-spreker hom nie teen God verhef nie deur van 'n retoriese vraag gebruik te maak. Deur hierdie werkswyse ontlok hy by die leser net een moontlik antwoord: nee, die ek-spreker sal hom nie teen die Here verhef nie. Die retoriese vraag staan dus hier in diens van effektiewe kommunikasie.

Die Hebreeuse psalm se tweede en derde versreëls vind neerslag in Cloete se tweede strofe. Cloete doen in die omdigting reg aan die pragtige vergelyking van 'n kind wat by sy ma rus vind en die ek-spreker in die psalm wat by die Here vrede kry. Die paranetiese derde versreël in die Hebreeuse psalm word ook in dié vorm by die Cloete-omdigting aangetref. Met 'n dubbele "wag" word die oproep in die omdigting versterk. Die vertroue wat moet aanhou, word ook deur 'n sinonieme begrippepaar bevestig: "deurentyd" en "tot in ewigheid". Deurdat die twee begrippe in die eindrymposisie geplaas is, kry hulle 'n fokus wat die duratiewe aard van die vertroue in die Here bevestig.

\section{9. 'n Slotwoord}

In hierde artikel is gepoog om die sentrale belang van die psalms in die liturgie aan die lig te bring. Die waarde van die Psalms as liedboek is ook onderstreep. Ten einde die plek van die verskillende psalms te begryp, is die Psalms as digbundel gerespekteer. Daar is ook aan die samestelling 
van die psalmbundel en die literatuursoorte aandag gegee. Uit die analise van die Cloete-omdigting is die hoë literêre waarde van dié omdigting aangetoon.

\section{Bibliografie}

BARNARD, AC. 1985. Die erediens. Pretoria : NG Kerkboekhandel.

BEYERLIN, W. 1982. Wider die Hybris des Geistes. Studien zum 131. Psalm. Stuttgart : Verlag Katholisches Bibelwerk. (SBS 108.)

KASPAR, P.P. 1999. Musica sacra: Das grosse Buch der Kirchenmusik. Wenen : Styria.

KRAUS, H.-J. 1966. Psalmen. 2. Teilband. 3. unveränd. Aufl. Neukirchen-Vluyn : Neukirchener Verlag. (BKAT XV/2.)

LIEDBOEK VAN DIE KERK. 2001. Kaapstad : NG Kerk-Uitgewers.

MONSMA, D. 1998. Informatie en documentatie. (In Oskamp, P. \& Schuman, N., reds. De weg van de liturgie: Tradities, achtergrond, praktijk. Zoetermeer : Meinema. p. 423-435.)

PRINSLOO, W.S. 1984. Van kateder tot kansel. 'n Eksegetiese verkenning van enkele psalms. Pretoria : NG Kerkboekhandel.

PRINSLOO, W.S. 1991. Die Psalms leef! Pretoria : NG Kerkboekhandel.

SCHUMAN, N.A. 1995. "... en wat zij zong hoorde ik dat psalmen waren". Over psalmen en liturgie. Kampen. (Intreerede, 22 September 1995.)

SCHUMAN, N.A. 1998a. De Psalmen. (In Oskamp, P. \& Schuman, N., reds. De weg van de liturgie: Tradities, achtergronden, praktijk. Zoetermeer : Meinema. p. 165-175.)

SCHUMAN, N.A. 1998b. “... Die weet gehad heeft en geen weet had”. Skrif en Kerk, 19(2):373- 380.

SCHUMAN, N.A. 2001. Psalm 90: tekst, context, en een diversiteit aan herlezingen. (In Jaarboek voor Liturgie-ondersoek. Instituut voor Liturgietetenschap. Groningen Liturgisch Instituut : Tilburg. p. 237-252.)

SEYBOLD, K. 1996. Die Psalmen: HAT 1/15. Tübingen : Mohr \& Siebeck. (HAT 1/15.)

VAN DER PLOEG, J.P.M. 1974. Psalmen II (Psalm 76-150). Roermond : Romen \& Zonen. (BOT.)

VIVIERS, H. 1998. "Jy is net 'n sandkorrel, maar só is alle mense" - Nadenke oor Psalm 131. Skrif en Kerk, 19(3):676-685.

VOS, C.J.A. 1996. Die volheid daarvan 11. Pretoria : Die Raad vir Geesteswetenskalike Navorsing Uitgewery.

VOS, C.J.A. 2001. 'n Perspektief op die nuwe Psalmomdigting. Hervormde Teologiese Studies, 56(2 - 3):357-376.

VRIJLANDT, M.A. 1989. Liturgiek. 's-Gravenhage : Meinema.

ZENGER, E. 1997. Die Nacht wird leuchten wie der Tag. Freiburg : Herder.

\section{Kernbegrippe:}

omdigting van Psalm 131

Psalms as 'n digbundel

Psalms en himnologie

Psalms en liturgie
Key concepts:

Psalms and himnology

Psalms and liturgy

Psalms as a collection of poems

versification of Psalm 131 